\title{
Endoscopic removal of two magnets impacted in the lower esophagus and gastric fundus
}

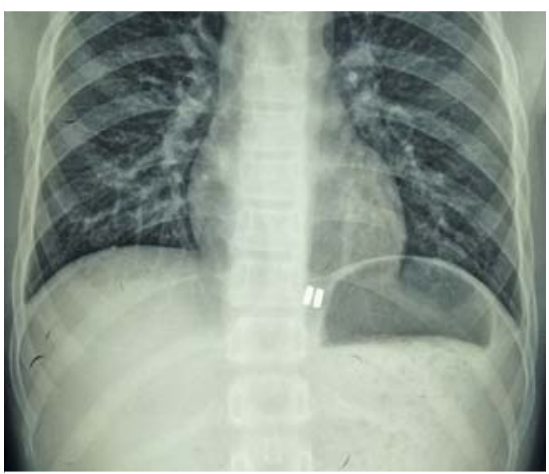

- Fig. 1 Radiograph taken on the first day showing the two separate magnets in the lower esophagus and gastric fundus, and an apparent break in the gastric mucosa.

A 13-year-old healthy child was referred with a 12-day history of epigastric pain following the inadvertent ingestion of two round magnets. Radiographic inspection on the first day demonstrated two separate foreign bodies in the lower esophagus and gastric fundus (- Fig.1), which did not pass spontaneously after 3 days of follow-up. Upper gastrointestinal endoscopy on the fourth day revealed the formation of an esophagogastric fistula ( $>$ Fig.2), but conventional endoscopic methods failed to remove the impacted magnets after repeated attempts. The patient and his parents refused a surgical operation, therefore another endoscopic intervention was performed.

Preprocedural radioscopy identified that the two magnets were close together. An endoscopic radial incision was initially made at the gastric opening of the fistula using an IT-knife and a Hook-Knife ( $\triangleright$ Video 1). This revealed that the magnets were located in the muscular layer. Grasping forceps were then used to try to grasp the magnets, but this also failed. To avoid further iatrogenic injury and having obtained informed consent from his parents, a special apparatus consisting of a powerful ring-shaped sterilized magnet with string attached
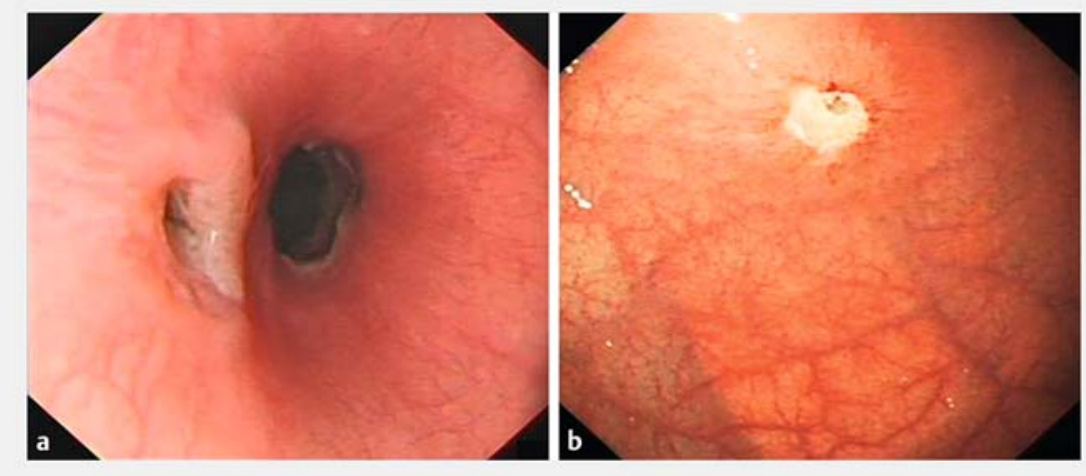

Fig. 2 Upper gastrointestinal endoscopy views showing: a the esophageal opening of the fistula; $\mathbf{b}$ the gastric opening of the fistula.

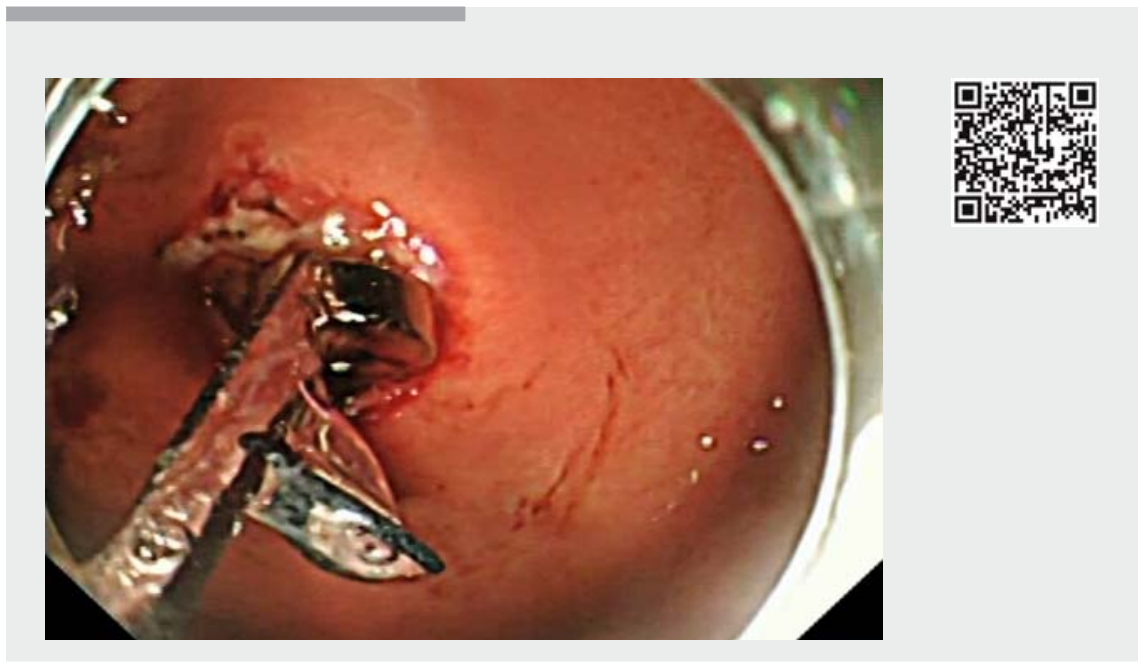

$\checkmark$ Video 1 Endoscopic removal of two magnets impacted in the lower esophagus and gastric fundus.

was selected. The device was carried into the gastric lumen using forceps and the impacted magnets were easily removed once they had been drawn together ( $>$ Fig.3). The incision was closed by means of purse-string suture. The patient started eating on postoperative day 3 and no complications were noted. Endoscopic re-examination on day 7 also showed significant improvement of the fistula (> Fig.4).
Gastrointestinal injuries caused by ingested magnets can be severe or even fatal [1]. It is suggested that all ingested magnets should be removed urgently whenever possible [2-4]. In the present case, the discomfort and the first radiograph after ingestion suggested that the attractive force between the two magnets had trapped a portion of the esophagogastric wall. Although successful removal of the magnets was achieved with 


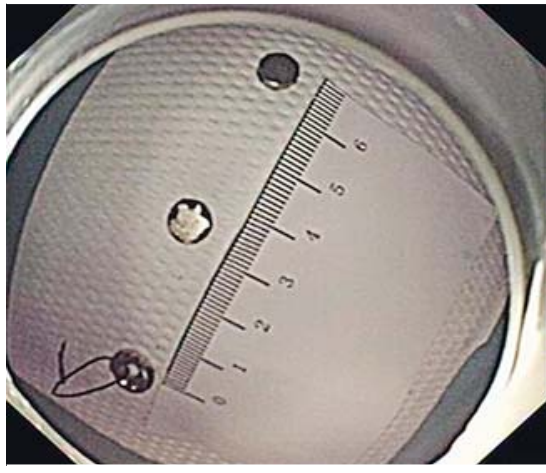

- Fig. 3 The impacted magnets following their successful removal.

the use of another magnet, emergent endoscopy might have reduced the injury and avoided fistula formation.

Endoscopy_UCTN_Code_TTT_1AO_2AL

\section{Competing interests}

None

The authors

Liansong Ye* , Zhengbing Yang*, Jiang Du, Qishan Zeng, Xianglei Yuan, Yuhang Zhang, Bing $\mathrm{Hu}$

Department of Gastroenterology, West China Hospital, Sichuan University, China

* Co-first authors.

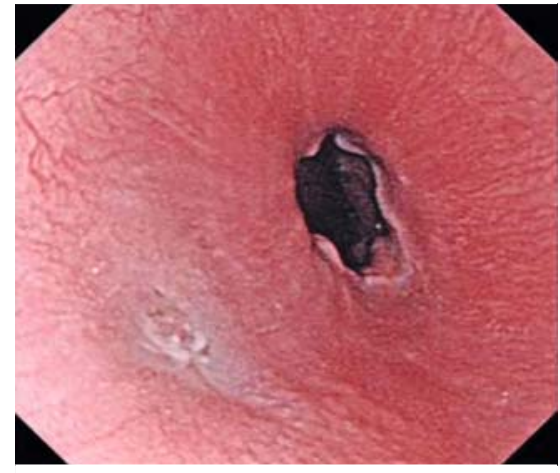

- Fig. 4 View during endoscopic re-examination showing healing of the esophageal mucosa.

\section{Corresponding author}

\section{Bing Hu, MB}

Department of Gastroenterology, West

China Hospital, Sichuan University, No. 37

Guo Xue Alley, Chengdu 610041, Sichuan

Province, China

hubingnj@163.com

\section{Acknowledgments}

We acknowledge the help of the Department of Gastroenterology and Endoscopy Center of West China Hospital in the management of our patient.

[1] Centers for Disease Control and Prevention. Gastrointestinal injuries from magnet ingestion in children - United States, 2003 2006. MMWR 2006; 55: $1296-1300$

[2] Butterworth J, Feltis B. Toy magnet ingestion in children: revising the algorithm. J Pediatr Surg 2007; 42: e3-e5

[3] Ikenberry SO, Jue TL, Anderson MA et al. Management of ingested foreign bodies and food impactions. Gastrointest Endosc 2011; 73: $1085-1091$

[4] Birk M, Bauerfeind P, Deprez PH et al. Removal of foreign bodies in the upper gastrointestinal tract in adults: European Society of Gastrointestinal Endoscopy (ESGE) Clinical Guideline. Endoscopy 2016; 48: 489-496

\section{Bibliography}

DOI https://doi.org/10.1055/s-0044-101703

Published online: 21.2.2018

Endoscopy 2018; 50: E124-E125

(c) Georg Thieme Verlag KG

Stuttgart · New York

ISSN 0013-726X

\section{ENDOSCOPY E-VIDEOS}

https:|/eref.thieme.de/e-videos

口回 Endoscopy E-Videos is a free

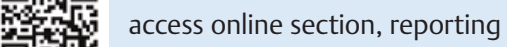
靣和: on interesting cases and new techniques in gastroenterological endoscopy. All papers include a high quality video and all contributions are freely accessible online.

This section has its own submission website at https://mc.manuscriptcentral.com/e-videos 